Harvard Data Science Review • Issue 2.3, Summer 2020

\title{
Data Science for Everyone Starts in Kindergarten: Strategies and Initiatives From the American Statistical Association
}

\section{Wendy Martinez ${ }^{1}$ Donna LaLonde ${ }^{2}$}

${ }^{1}$ Mathematical Statistics Research Center, Bureau of Labor Statistics, Washington, District of Columbia, United States of America,

${ }^{2}$ Strategic Initiatives and Outreach, American Statistical Association, Alexandria, Virginia, United States of America

Published on: Sep 15, 2020

DOI: https://doi.org/10.1162/99608f92.7a9f2f4d

License: Creative Commons Attribution 4.0 International License (CC-BY 4.0). 


\section{ABSTRACT}

The American Statistical Association (ASA) is committed to supporting and enhancing statistics and data science education at all levels, from early grades to the $\mathrm{PhD}$. Attitudes about statistics and mathematics form early, so it is critical to ensure that students in the elementary grades have positive and meaningful statistics and data science education experiences. Provided with the appropriate resources and support, elementary educators will be able to create data-rich learning environments and establish the foundation for future success. This is the motivation for the focus on grades K-6 for the current education initiative, which in the United States is kindergarten (age 5) through sixth (age 11 to 12) grade levels. In this article we explore some of the ASA's achievements and current efforts to inspire future data scientists by expanding elementary education resources.

Keywords: K-12 education, Common Core, mathematics, statistics, learning resources

\section{Why Should Data Science Education Start in Kindergarten?}

"How do we ensure that students have flexible problem-solving skills to tackle future problems using data with techniques and technology that may not yet exist?” This question was posed in an editorial introducing a special issue of The American Statistician, the focus of which was the changes required for undergraduate education to keep up with a new world of data and increased demand for statisticians (Horton \& Hardin, 2015). The same question is perhaps more important to ask of the $\mathrm{K}-12$ (kindergarten to 12th grade) curriculum, the earlier stages of the education system when students make decisions about the subjects they're interested in, and when the basis of future understanding is laid out. The American Statistical Association's (ASA) answer to ensuring that students are prepared for the world they will enter is to begin data science education in kindergarten.

A recent consensus report from the National Academies of Sciences, Engineering, and Medicine (2018) identified a key goal of undergraduate data science education: "to give all students the ability to make good judgments, use tools responsibly and effectively, and ultimately make good decisions using data.” The committee defined these fundamental abilities as "data acumen,” skills that all people need to be educated citizens in a data-driven world. However, beginning to pursue data acumen in undergraduate education is not enough. Complementary goals, starting when students enter school for the first time at age 5 to 6 , are necessary to make the undergraduate goal a reality. All students should begin to develop data acumen then, so that they can conclude their secondary education with the skills and abilities necessary to continue their education and ultimately be successful in careers requiring data insights, and be responsible global citizens. As stated in the Pre-K-12 Guidelines for Assessment and Instruction in Statistics Education II (GAISE II): "Students need to begin at an early age to become data-savvy, whether working with small data sets or large, messy data sets, 
traditional data, or non-traditional data such as text or images. Most future jobs will require some knowledge of statistics and data analytics” (Bargagliotti \& Franklin, et al., in press). The number of jobs that require data scientists of some kind is growing exponentially, and to fulfill this future need, students need to begin learning as soon as they can.

With the current lack of positive experiences with data science in the early school system, too often, students in undergraduate school arrive with a dislike (and even fear) of statistics and mathematics, and sometimes this attitude is well-established by the time children get to middle school. The earlier that these skills and ideas are presented to students in a positive light, the more likely they will become more interested in these fields and pursue them in the future. Fundamental additions and changes are needed in early data science education to ensure that students are not turned off from these essential fields.

\section{American Statistical Association Initiatives: Past, Present, and Future}

The ASA was formed in 1839 in Boston—a city burgeoning with educational, technical, and professional opportunities at the time. What started with just five founders soon began to attract hundreds of members. The ASA had ties to the statistical work of the U.S. government, particularly the Census Bureau, which incited a movement led by then-ASA president Francis A. Walker (1883-1897) to expand the association nationwide. Today, the ASA's membership exceeds 17,000 professionals in academia, government, research, and business. It consists of more than 70 chapters, nearly 30 sections, 17 journals, and six yearly conferences. Throughout all the growth and change, the ASA's mission remains the same: to promote the practice and profession of statistics.

The association developed a strategic plan to achieve its mission. The plan lays out three overarching themes: (1) Enhancing the Diversity and Breadth of our Association, (2) Increasing the Visibility of our Profession, and (3) Ensuring the Future of our Profession. Education is a key component of the third theme, and we would argue it is a cornerstone of ASA's vision to realize $a$ world that relies on data and statistical thinking. The important work needed to reach this vision begins in kindergarten classrooms across the United States.

The ASA has a longstanding commitment to providing educational resources and supporting $\mathrm{K}-12$ education, though in the past efforts have concentrated on middle and high school levels (ages 11-18). The ASA's presidential initiatives have generated important contributions to further the themes in the strategic plan. For example, 2016 ASA president Jessica Utts created an initiative to provide information on careers in statistics to students taking the Advanced Placement Statistics course, as well as other high school students, teachers, counselors, and parents.

Utts charged a working group to curate and develop resources for ASA members to use in outreach activities with K-12 students. As part of the initiative, an ASA web page was created to address these areas and more. 
Outreach is essential to help make students aware of the opportunities available to them, as well as encourage them to pursue data science by providing essential information. As students engage in the formal curriculum in their classrooms, they ask questions like "What does a data scientist do?" and "How do you prepare for a career as a data scientist?” Members of the ASA are able to provide authentic answers to these questions and can partner with teachers to guide students throughout their education.

Continuing with Utts's educational focus, 2017 ASA president Barry Nussbaum (2018) had an initiative called the House of Statistics-Explore, Engage, and Learn. Nussbaum's efforts focused on middle school students and educators, and his working group developed the website http://www.houseofstatistics.org/. This website has videos, links to resources, games, and more. A collaborative effort with Laber Labs, this site introduces statistics and data science to mainly middle school students using entertaining and engaging educational videos and games. Continuing the goal to have initiatives build on earlier work, the team working on the current K-6 initiative will add content to the site.

These previous efforts focused on middle and high school students, but we know that the mission of promoting the practice and profession of statistics must begin before middle school. It is essential that we introduce children to concepts associated with analyzing data and statistical literacy at an earlier age. The ASA will collaborate with teachers on this initiative to develop learning environments that support their teaching practices, so we can be good partners to educators and integrate resources into the existing curriculum.

\section{ASA Educational Outreach Activities}

We have described some of the ongoing ASA student-centered activities, but there is a lot more going on—-too much to list in this article. In this section, we want to highlight activities that will inform the 2020 ASA initiative on $\mathrm{K}-6$ education.

Because K-12 education is such an important part of ASA's mission, the ASA board of directors created the special position of K-12 statistical ambassador to lead the charge. Christine Franklin was appointed in 2016 and continues to guide the creation of professional development materials for educators and teachers, conduct workshops, engage in outreach to the STEM educational community, and much more. ASA members will be working with Franklin in 2020 to expand her efforts with the early grades.

For many years now, the ASA has sponsored a special workshop for middle and high school teachers, which is held at the Joint Statistical Meetings (JSM). Since JSM takes place in late summer, it is possible for teachers to attend the workshop. This workshop is called Meeting Within a Meeting (MWM) and focuses on statistics for middle and high school mathematics and science teachers. Teachers engage in active learning to augment their ability to teach statistics within the Common Core State Standards (CCSS) (2010) and the Next Generation Science Standards. Attendees can earn professional development credit by attending the MWM. The ASA is exploring options for expanding the MWM to include a K-6 component. 
Data challenges are a great way to introduce students to the fun of data science and statistics. The ASA sponsors several data challenges suitable for high school students. The annual Fall Data Challenge for high school and college students hosted at This is Statistics typically focuses on a call to address real problems affecting our society. The 2019 Fall Data Challenge used data from the U.S. Department of Housing and Urban Development (HUD) and asked the students to develop insights into ways to address homelessness in Los Angeles, New York City, and Seattle. A spring competition—Statsketball— keeps the excitement going throughout the school year. This contest uses statistics to make predictions about the NCAA basketball tournament. What's Going On in This Graph? is a weekly feature produced by the New York Times Learning Network and the ASA. This feature asks middle and high school students to look at graphs and to become critical consumers of these visualizations. In 2020, we are exploring the option of developing data challenges appropriate for K-6 students. The theme for JSM 2020 is Everyone Counts: Data for the Public Good, and we hope to continue this theme beyond JSM by engaging students in challenges to advance their understanding of data and expose them to its numerous capabilities.

A goal of the 2020 initiative is to make the list of $\mathrm{K}-12$ resources on the ASA website more comprehensive. Federal statistical agencies such as the Census Bureau and the Bureau of Labor Statistics (BLS) have web pages with resources for educators, like the BLS's Kids Page, which contains games, career information, and how-tos for kids, as well as resources for teachers. The ASA also hosted the Census at School project, which provides an opportunity for students to analyze census-related data and problems. Adding these resources and more to the ASA website will help these future researchers and their teachers learn about available data sources.

\section{Focus on K-6: Ideas and Projects}

"Classify objects into given categories; count the numbers of objects in each category and sort the categories by count” (CCSS). This describes one of the Kindergarten Measurement and Data standards from the Common Core State Standards for Mathematics. This standard illustrates that primary students are in fact data scientists; they are learning to use "group by.” The ASA's overarching goal for this initiative is to support teachers and caregivers as they begin the data science education of children as young as 5 and 6 .

The ASA has already presented some ideas for the new K-6 initiative that work in conjunction with current educational outreach efforts and the development of a resource repository. But the new initiative is also starting projects that go into new territory, beyond the existing efforts.

One of these projects is a collaboration with the Stats+Stories podcast team. Wendy Martinez, the current ASA president, joined John Bailer, the co-creator of Stats+Stories and the chair of the Department of Statistics at Miami University in Oxford, Ohio, for a podcast during which they were interviewed by two middle school students. The ASA hopes to have many more conversations with students to understand their thinking and what they want to learn more about. Though this project currently focuses on early middle school students, the ASA hopes to expand it in the future to include even younger students in elementary grades. 
Research suggests that fun and informational games are effective resources for teaching and learning at all levels (Qian \& Clark, 2016). To help celebrate Mathematics and Statistics Awareness Month (MSAM) and as part of this presidential initiative, the ASA launched a game development challenge for professionals to design games for students to play. As the challenge encouraged creativity, the game could be a board game, card game, video game, or Shiny app like the Correlation Game. Although the initiative was focused on $\mathrm{K}-6$, the game could be designed for any age level to play.

The Correlation Game, STEM Jeopardy, and the Laber Lab video games highlighted in the 2020 MSAM poster are great examples, but more educational games are needed. The ASA is asking participants to work with colleagues or independently to generate ideas for types of games. A panel will judge all the submissions and prizes will be awarded. Submissions will be accepted until December 31, 2020. Go to https://bit.ly/32166I7 to respond to the challenge. The competition calls for current professionals to not only become more aware of the next generation of data scientists but also create resources for students to actually use.

\section{Conclusion}

The BLS publishes employment projections 10 years into the future. The latest publication from the BLS projects employment (in the United States) for detailed occupations out to 2028. We thought it would be interesting to look at the list of the fastest growing occupations because educating job seekers for employment 10 or more years from now needs to start in the early grade levels.

According to these projections, a statistician is one of the fastest growing professions with the number of jobs increasing by 35 percent. Some related occupations, such as data scientist and operations research analyst, are also projected to increase-by 31 percent and 25 percent, respectively. The estimated increases in employment for these fields highlight the critical need to ensure a pipeline of individuals prepared for careers in statistics and data science. We are convinced that an effective pipeline begins with elementary students. Learning mathematics and statistics is a developmental process, so we want elementary students to have appropriate, positive early learning experiences.

The ASA will continue to devote resources and time to educational outreach and development efforts, as this is one of its strategic goals. We have outlined just some of the possible ideas for our K-6 initiative; the President's Corner in the August 2020 issue of the AMSTAT News provides more details and links to resources (Martinez, 2020). We are always looking for new ideas and resources, and we welcome any you might have. We are particularly interested in hearing from our international colleagues because ensuring our future through education should be a global priority. Feel free to email Donna LaLonde at ASA (ㅁonnal@amstat.org) with your ideas. 


\section{Acknowledgments}

We would like to thank Xiao-Li Meng for giving us this opportunity to describe important efforts to foster statistics education at early ages and for his patience as we revised this article. We thank the reviewers for their insightful comments, especially the reviewer who did a wonderful job making edits. The comments resulted in a much-improved publication.

For more on all of the educational resources and opportunities, see the ASA website.

More details and highlights of Christine Franklin's efforts are also available on the website.

\section{Disclosure Statement}

Wendy L. Martinez and Donna LaLonde have no financial or non-financial disclosures to share for this article.

\section{References}

Bargagliotti, A., \& Franklin, C., et al. (in press). Pre-K-12 guidelines for assessment and instruction in statistics education II (GAISE II).

Horton, N. J., \& Hardin, J. S. (2015). Teaching the next generation of statistics students to "think with data." The American Statistician, 69(4), 259-265. https://doi.org/10.1080/00031305.2015.1094283

Martinez, W. (2020, August 1). Does anyone still used colored chalk? AMSTAT News.

https://magazine.amstat.org/blog/2020/08/01/colored-chalk-new-school-year/

National Academies of Sciences, Engineering, and Medicine. (2018). Data science for undergraduates:

Opportunities and options. Washington, DC: The National Academies Press. https://doi.org/10.17226/25104

National Governors Association Center for Best Practices, Council of Chief State School Officers. (2010). Common Core state standards mathematics. http://www.corestandards.org/Math/

Nussbaum, B. D. (2018). Statistics: Essential now more than ever. Journal of the American Statistical Association, 113(522), 489-493. https://doi.org/10.1080/01621459.2018.1463486

Qian, M., \& Clark, K. (2016). Game-based learning and 21st century skills: A review of recent research. Computers in Human Behavior, 63, 50-58. https://doi.org/10.1016/j.chb.2016.05.023

(C2020 Wendy L. Martinez and Donna LaLonde. This article is licensed under a Creative Commons Attribution (CC BY 4.0) International license, except where otherwise indicated with respect to particular material included in the article. 